\title{
Recognition failures and free-recall failures: Implications for the relation between recall and recognition
}

\author{
JOHN M. GARDINER \\ The City University, London, England
}

\begin{abstract}
Experiments showing that in cued recall subjects can recall words that they had previously failed to recognize have been taken to refute generate-recognize theories of recall, for those theories predict that recall is dependent on recognition. None of these experiments, however, has provided an appropriate test of Bahrick's $(1970,1979)$ generate-recognize theory, which explicitly refers to words that are accessible to cued recall but not to free recall, that is, to free-recall failures. When the experimental procedure was modified so as to provide tests of this theory, no evidence was found of any greater dependency between recall and recognition of free-recall failures than between recall and recognition overall. Free-recall failures do not, therefore, constitute any exception to many previous experimental findings that conform with the Tulving-Wiseman law, and so the account offered by Bahrick's generate-recognize theory may be rejected. The results also suggest an explanation for some other conflicting evidence on whether recall and recognition are dependent or independent.
\end{abstract}

In essence, generate-recognize theory assumes that whereas recall involves both generate and recognize stages, recognition involves only the recognize stage, and therefore the theory assumes that the relation between recall and recognition is one of dependency, with success at recall being dependent on success at recognition. To test this prediction, Tulving and his associates (Tulving \& Thomson, 1973; Watkins \& Tulving, 1975) devised a procedure in which subjects study a list of B words in the context of $A$ words and are then tested successively for recognition of $B$ words and for recall of $B$ words given the $\mathrm{A}$ words as cues. The procedure revealed that subjects typically are able to recall quite a few B words that they fail to recognize, thereby demonstrating that recall is not dependent on recognition. This phenomenon of recognition failure of recallable words has since been studied intensively, and it has led to a number of fresh theoretical developments, but its initial importance lay in the fact that its occurrence was instrumental in persuading a number of researchers that the generate-recognize theory of recall was incorrect and should be rejected (for reviews, see Kintsch, 1974; Tulving, 1976, 1983; Watkins \& Gardiner, 1979).

Not all researchers, however, have accepted that the occurrence of recognition failure of recallable words is critical for the generate-recognize theory. Kintsch (1978), for example, pointed out that there is evidence suggesting that subjects may adopt a more lenient response criterion in recall than in recognition and that this difference in criterion allows some words through the recognize

I am greatly indebted to Endel Tulving, and also to Gregory Jones, for helpful discussion. Requests for reprints should be addressed to John Gardiner, Memory \& Cognition Research Group, The City University, Northampton Square, London ECIV OHB, England. stage at recall that were not allowed through the recognize stage at recognition. As Kintsch (1978) made clear, however, his purpose in pointing this out was not to defend generate-recognize theory, and certainly not his own earlier formulation of the theory, but merely to argue that generate-recognize theory is not necessarily inconsistent with recognition failure of recallable words. And it seems from a number of other considerations that the assumption of differences in response criteria in the recognize stage at recall and at recognition does not enable the theory to give an adequate account of the phenomenon (see, e.g., Watkins \& Gardiner, 1979).

A second, more serious, challenge to the view that the phenomenon of recognition failure of recallable words is inconsistent with generate-recognize theory has been made by theorists who have assumed that access may be gained to different word senses or meanings in the recognition and cued-recall tests (e.g., Martin, 1975; Reder, Anderson, \& Bjork, 1974). The assumption is that most words have multiple representations in semantic memory, each representation corresponding with a different word meaning, and that recognition failure occurs because sometimes the meaning encoded on encountering a word in the recognition test is not the meaning that was encoded at study and to which access is again obtained in the cuedrecall test.

This theory predicts that recognition failure of recallable words should not occur for words of single meaning. Because such words have only a single representation in semantic memory, there is no possibility of gaining access at test to a different representation from that encoded at study. Tulving and Watkins (1977) tested this prediction with words of single meaning as defined operationally from dictionary entries (e.g., COCONUT, HAND- 
SHAKE, HOLSTER), and they found not only that recognition failure occurred, but that it was quite comparable in magnitude with that obtained with other words. However, Muter (1984) subsequently argued that the words used by Tulving and Watkins may not have had unique representation in semantic memory, and, using words of single meaning that were unique names of famous people (e.g., ATATURK, BIZET, HAMMARSKJOLD), he obtained the predicted result: no recognition failure of recallable words. Muter's experiment, however, was a semantic rather than an episodic memory experiment; he did not initially present the names in a study list alongside context items that were later used in cued recall. In contrast, Nilsson, Law, and Tulving (1988) showed that with episodic rather than semantic memory tests, recognition failure of recallable words did occur for unique famous names, and, moreover, that it occurred to much the same extent for them as for other words. Muter's (1984) results, therefore, must have depended on particular experimental conditions and not on the semantic properties of the words, as assumed by generate-recognize theory. Other empirical problems for this theory, and certain conceptual difficulties that it entails, were discussed by Watkins and Gardiner (1979).

A third major challenge to the conclusion that generaterecognize theory cannot account for the phenomenon of recognition failure of recallable words was made by Bahrick (1979) in connection with his own very influential generate-recognize theory (Bahrick, 1970). Bahrick (1979) pointed out that the experimental procedure that gives rise to the phenomenon does not provide an appropriate test of his theory, because the theory is explicitly limited to retrieval of information not accessible to free recall. Because much information in free recall seems to be retrieved without effort, Bahrick's theory assumes that much of the information retrieved in free recall is retrieved directly, without involving a search process. The generate stage is assumed to be involved largely in the retrieval of information not accessible to free recall. Hence, tests of the theory had to be limited to what Bahrick (1979) termed free-recall failures, that is, words accessible in cued recall but not in free recall. The relation between overall cued recall and recognition, as examined in previous experiments, is therefore not critical for this theory. It is for free-recall failures that recall should be largely, if not completely, dependent on recognition.

Although Bahrick's (1970) generate-recognize theory has continued to be influential (see, e.g., Glass \& Holyoak, 1986; Gregg, 1986), rather surprisingly no direct tests of its predictions with respect to recognition failure of recallable words seem to have been reported. The purpose of the present article is to describe two experiments that provide such tests: that is, given that previous studies of recognition failure are not relevant to the theory, and that "the general situation dealt with by the model is one in which free recall has failed to produce a previously learned response" (Bahrick, 1979, p. 148; see also Bahrick, 1970), the aim was to determine the relation between the recall and recognition of free-recall failures in an appropriate modification of the procedure that typically gives rise to recognition failure of recallable words.

Of course, even if it were to turn out that Bahrick's $(1970,1979)$ theory is supported, it is unlikely that this outcome would alter previous interpretations of other versions of generate-recognize theory, or significantly change the fate of the theory as a whole. But there is an additional, more compelling reason for testing the theory's predictions with respect to recognition failure. This is the need to know whether, as the theory predicts, freerecall failures constitute an exception to the TulvingWiseman law (Tulving \& Wiseman, 1975; see also Flexser \& Tulving, 1978; Tulving, 1983). The TulvingWiseman law is an empirical law, based on the results of many previous experiments, in which the incidence of recognition failure as expressed by its complement, the probability of recognition $(R n)$ given recall $(R c)$, is determined by the level of recognition as expressed by the hit rate. In quantitative form, the law is as follows:

$$
p(\mathrm{Rn} / \mathrm{Rc})=p(\mathrm{Rn})+.5\left[p(\mathrm{Rn})-p(\mathrm{Rn})^{2}\right] .
$$

Qualitatively, the relation embodied in this empirical law is that recall and recognition are largely, but not completely, independent. Flexser and Tulving (1978) accounted for this relation theoretically by a formal model in which recall and recognition are essentially independent. The model incorporates the encoding specificity principle at a featural level; it assumes that successful retrieval depends on the goodness of the match or overlap between features encoded at study and features encoded at test. Retrieval independence in this model refers to the lack of any correlation between features encoded from the copy cue in recognition and features encoded from the context cue in recall. Complete independence is not observed because of idiosyncratic encoding of study list items-particularly "good" and "bad" items for any individual subject will tend, respectively, to be both recognized and recalled, and to be neither recognized nor recalled.

Claiming the existence of an empirical law has necessarily involved intensive efforts to understand the few exceptions to it that have been reported (see, e.g., Gardiner \& Tulving, 1980; Jones \& Gardiner, 1988; Nilsson, Dinniwell, \& Tulving, 1987; Nilsson et al., 1988). “"Exceptions"' here means cases in which the observed probability of recognition given recall is notably greater than predicted, and which do not seem attributable to random fluctuation or other source of error; if such exceptions cannot be understood and explained in terms of the conditions determining the law, then the law itself is undermined. From this standpoint, Bahrick's $(1970,1979)$ generate-recognize theory, like other versions of generaterecognize theory, challenges the law. It predicts exceptions under conditions in which, according to our understanding of the law, there is no reason to expect them.

There is one further point of interest in the present experiments. They also have implications for two other sets of studies that, using rather different procedures, reached 
Table 1

Recognition (Rn), Recall (Rc), and Recognition Given Recall in Experiments 1 and 2

\begin{tabular}{|c|c|c|c|c|c|c|c|c|c|c|}
\hline & \multirow[b]{2}{*}{ Recognition } & \multirow[b]{2}{*}{ Recall } & \multicolumn{4}{|c|}{$2 \times 2$ Contingencies } & \multicolumn{4}{|c|}{ Recognition Given Recall } \\
\hline & & & $R \cap R c$ & $\operatorname{Rn} \overline{R c}$ & $\overline{\mathbf{R n} R c}$ & $\overline{\mathbf{R n}} \overline{\mathbf{R c}}$ & Observed & Expected & O-E & $\overline{S E M}$ \\
\hline \multicolumn{11}{|l|}{ Experiment 1} \\
\hline $\begin{array}{l}\text { Cued Recall Overall } \\
\text { Free-Recall Failures }\end{array}$ & $\begin{array}{l}.732 \\
.616\end{array}$ & $\begin{array}{l}.662 \\
.542\end{array}$ & $\begin{array}{l}.555 \\
.391\end{array}$ & $\begin{array}{l}.177 \\
.225\end{array}$ & $\begin{array}{l}.107 \\
.151\end{array}$ & $\begin{array}{l}.161 \\
.233\end{array}$ & $\begin{array}{l}.838 \\
.721\end{array}$ & $\begin{array}{l}.830 \\
.735\end{array}$ & $\begin{array}{r}.008 \\
-.014\end{array}$ & $\begin{array}{l}.024 \\
.043\end{array}$ \\
\hline \multicolumn{11}{|l|}{ Experiment 2 (Strict) } \\
\hline $\begin{array}{l}\text { Cued Recall (Control) } \\
\text { Cued Recall Overall } \\
\text { Free-Recall Failures }\end{array}$ & $\begin{array}{l}.524 \\
.562 \\
.462\end{array}$ & $\begin{array}{l}.573 \\
.618 \\
.538\end{array}$ & $\begin{array}{l}.389 \\
.413 \\
.302\end{array}$ & $\begin{array}{l}.135 \\
.149 \\
.160\end{array}$ & $\begin{array}{l}.184 \\
.205 \\
.236\end{array}$ & $\begin{array}{l}.292 \\
.233 \\
.302\end{array}$ & $\begin{array}{l}.679 \\
.668 \\
.561\end{array}$ & $\begin{array}{l}.649 \\
.685 \\
.587\end{array}$ & $\begin{array}{r}.030 \\
-.017 \\
-.026\end{array}$ & $\begin{array}{l}.027 \\
.038 \\
.042\end{array}$ \\
\hline \multicolumn{11}{|l|}{ Experiment 2 (Lenient) } \\
\hline $\begin{array}{l}\text { Cued Recall (Control) } \\
\text { Cued Recall Overall } \\
\text { Free-Recall Failures }\end{array}$ & $\begin{array}{l}.684 \\
.715 \\
.603\end{array}$ & $\begin{array}{l}.646 \\
.635 \\
.563\end{array}$ & $\begin{array}{l}.531 \\
.510 \\
.387\end{array}$ & $\begin{array}{l}.153 \\
.205 \\
.216\end{array}$ & $\begin{array}{l}.115 \\
.125 \\
.176\end{array}$ & $\begin{array}{l}.201 \\
.160 \\
.221\end{array}$ & $\begin{array}{l}.822 \\
.803 \\
.687\end{array}$ & $\begin{array}{l}.792 \\
.817 \\
.723\end{array}$ & $\begin{array}{r}.030 \\
-.014 \\
-.036\end{array}$ & $\begin{array}{l}.026 \\
.020 \\
.032\end{array}$ \\
\hline
\end{tabular}

opposite conclusions about whether the relation between recall and recognition is one of dependence (Watkins \& Todres, 1978) or independence (Broadbent \& Broadbent, 1975). The results of the present experiments suggest an explanation for this previously unresolved discrepancy.

\section{EXPERIMENT 1}

Bahrick (1979) suggested that what is required to test his theory is a prior free-recall test so that words accessible to each subject in free recall can be excluded in examining cued-recall performance. Accordingly, in Experiment 1 the experimental procedure that gives rise to recognition failure was modified in that following the recognition tests subjects were given a free-recall test before being tested for cued recall. For each subject, cued recall and recognition performance overall was then evaluated and compared with cued recall and recognition of free-recall failures, that is, excluding the words subjects produced in free recall. Overall cued-recall and recognition performance should yield normal results, replicating the many other experimental results that conform with the Tulving-Wiseman law. The predictions from Bahrick's $(1970,1979)$ theory are either that cued recall and recognition of free-recall failures should be completely dependent, or at least that for free-recall failures, cued recall should be more dependent on recognition than it is for cued recall and recognition overall.

\section{Method}

Subjects. The subjects were 16 undergraduate students at The City University, London, who were paid for their participation in the experiment and were tested individually.

Design and Materials. Each subject studied a list of 24 A-B pairs of weakly associated words taken from the original materials used by Tulving and Thomson (1973). Two alternative lists were used; 8 subjects studied one list, and 8 studied the other list. Examples of items from one list are whiskey WATER, ant GIRL, glass HARD; examples of items from the other list are grasp BABY, glue CHAIR, bath NEED. The B items from both lists were mixed to form a single recognition test of 48 items. The subjects were given a free-choice recognition test. They were then tested for free recall of the $B$ items and then for recall of the $B$ items given the $A$ items as cues.
Procedure. The A and B items were presented in lowercase and uppercase letters, respectively, from an overhead projector at about the rate of one A-B pair every $2 \mathrm{sec}$. The subjects were instructed to study each A-B pair for a test in which the A items would be presented as cues for the recall of the corresponding B items. After presentation of the list, there was a 10 -min filler task to prevent overly high recognition performance. This consisted of an alphabetically ordered list of names of 96 countries; the subjects were asked to try to write down what they imagined the average person might first think of in connection with each country. The recognition test was then administered. The $\mathbf{4 8}$ test items were listed in two columns of 24 , and the subjects were instructed simply to work down each column in turn, circling any $B$ words they recognized from the study list. On completing this test, the subjects were handed a blank piece of paper and asked to write down, in any order they liked, all of the B words they could recall. Finally, they were given the cued-recall test, in which all the A items were listed, and the subjects were asked to recall again all the B words they could remember. All tests were self-paced.

Study list items, recognition test items, and cues were presented in constant orders, with a single random reordering of B items in the recognition test, and of $\mathrm{A}$ items in the cued-recall test.

Before the study list was presented, the subjects were given a practice list consisting of unique category names and instances, and this was directly followed by a cued-recall test in which the category names were presented as cues.

\section{Results}

The principal results are summarized in the first two rows of Table 1 . The first row shows data for overall cued recall and recognition. The second row shows recall and recognition data for free-recall failures, that is, for subjectitems not recalled in free recall. ${ }^{1}$ For these two subjectitem sets, the columns in Table 1 show the probability of recognition and of (cued) recall, a fourfold classification of recall and recognition contingency data, the observed and expected probability of recognition given recall, the mean difference between observed and expected values, and the standard errors of these means.

The predictions were that for free-recall failures, the probability of recognition given recall should be close to 1.00 , or that it should at least be appreciably greater than that obtained for overall cued recall and recognition. It is the difference between observed and expected probabilities of recognition given recall that is important for 
the Tulving-Wiseman law, and it is obvious from these differences that neither prediction was supported. $\mathrm{Ob}$ served and expected values were in close agreement for both free-recall failures $(.721$ vs. .735) and for overall cued recall (.838 vs. .830$)$. It also may be noted that the predictions were not supported even when the comparison is made in absolute terms rather than relative to the law. Indeed, in absolute terms there was less dependency for free-recall failures than for overall cued recall $(.721$ vs. .838). Thus there was no evidence in this experiment of more dependency in the relation between recall and recognition of free-recall failures than between overall cued recall and recognition.

\section{EXPERIMENT 2}

Experiment 2 was undertaken with the express purpose of obtaining two further replications of the principal findings from Experiment 1. In addition, a control group, for whom the free-recall test was omitted, was included in Experiment 2, although from the results of Experiment 1 it seems that the inclusion of a free-recall test did not materially affect the pattern of results obtained. Also, in order to obtain two sets of observations, the subjects in Experiment 2 completed each test in two successive phases: first, with instructions to adopt a strict, noguessing response criterion and, second, with instructions to adopt a lenient response criterion.

\section{Method}

Subjects. The subjects were 24 undergraduate students at the City University, London, who were paid for participating in the experiment and were tested individually. They were allocated arbitrarily to one of two equal groups.

Design and Procedure. For one group of 12 subjects, the design and procedure were similar to that in Experiment 1 . For the other (control) group of subjects, the free-recall test was omitted. Unlike Experiment 1, however, each test was carried out in two successive stages, first with strict instructions not to guess, and second with instructions that encouraged guessing.

\section{Results}

The principal results are summarized in the remaining rows of Table 1, first for the strict response criterion, and second for the lenient response criterion. For each criterion, the top row shows the control group data, and the second and third rows show data from the other group, as in Experiment 1.

Consider first the observed and expected probabilities of recognition given recall for free-recall failures. It is apparent that these values were again in close agreement, with .561 versus .587 for strict scoring and .687 versus .723 for lenient scoring. Similarly, there was little difference between observed and expected values for overall cued recall, with .668 versus .685 for strict scoring and .803 versus .817 for lenient scoring. Here, as in Experiment 1 , in absolute rather than relative terms the outcomes were counter to prediction; free-recall failures were less dependent on recognition, compared with overall cued recall, both for strict scoring (.561 vs. .668) and for lenient scoring (.687 vs. .803). Thus Experiment 2 replicated in full the principal findings from Experiment 1; there was again no evidence of greater dependency between recall and recognition of free-recall failures than between overall cued recall and recognition.

Second, it is apparent, from comparing cued-recall (control) data with cued recall overall, that the inclusion of the free-recall test had a negligible effect on performance and did not materially affect the pattern of results. It is also apparent that the instructional manipulation of response criterion had a large, and typical, effect on recognition performance, a negligible effect on recall, and little influence on the differences between the observed and expected probability of recall.

\section{GENERAL DISCUSSION}

In each of three replications, there was no evidence of any greater dependency between recall and recognition of free-recall failures than between cued recall and recognition overall. Free-recall failures were no exception to the many previous experimental findings that conform with the Tulving-Wiseman law. The account offered by Bahrick's $(1970,1979)$ generate-recognize model, therefore, may be rejected. It seems that this theory fares no better with respect to the phenomenon of recognition failure of recallable words than have other variants of generate-recognize theory.

This conclusion resulted from tests of Bahrick's (1970, 1979) model in an appropriately modified version of the procedure used in previous recognition failure studies. These tests leave open the question of what might happen if recognition failure were investigated in a modified version of the procedure used by Bahrick (1970) to support his model. This procedure involved paired-associate learning, followed by a prompted recall of previously unrecalled responses, in which extralist cues were used. In this prompted recall, the normative associative strength of the cue-target relation was varied systematically, and, as predicted by the model, recall was positively correlated with the strength of the association. However, this finding is also entirely consistent with the encoding specificity principle. The stronger the normative association is between the cue and its target, the more likely it is that features encoded from the cue will overlap with those initially encoded from the target at study (see, e.g., Tulving, 1983). If this overlap were substantial, however, then the Tulving-Wiseman law of recognition failure would be expected to break down. Recall would then become highly dependent on recognition, because the critical assumption of retrieval independence would be violated; features encoded from the copy cue in recognition would be correlated with features encoded from the recall cue (Flexser \& Tulving, 1978). To take an example from a rather similar situation in which evidence is available, features encoded in recognizing ATATURK as the name of a famous person are likely to be highly correlated with 
features encoded from the cue "First president of the republic of Turkey"' (Nilsson et al., 1988; see also Nilsson, et al., 1987). So what is now known about the Tulving-Wiseman law, and the exceptions to it, suggests that the use of extralist cues that are functionally almost equivalent to the presentation of the actual target should lead to recall's being highly dependent on recognition, but for reasons that are completely in keeping with the established boundary conditions of the law.

There is a further difficulty for Bahrick's $(1970,1979)$ theory. This concerns the complement of free-recall failures, that is, free-recall successes. Because the model was restricted to free-recall failures, the original generaterecognize theory prediction of dependency between recall and recognition was restricted to that subset of items; but what then of items that are free-recallable? They, too, cannot be assumed to be largely dependent on recognition, for then overall recall is dependent on recognition and the restriction vanishes. Thus it seems logical that the theory would have to assume that for free-recallable items, recall and recognition are largely independent. This assumption would also be necessary on empirical grounds, of course, if the theory were to account for the independence actually observed in the relation between cued recall and recognition.

In fact, the evidence for free-recall successes was that recognition and cued recall were largely, if not completely, dependent. Analysis of the recall-recognition relation for free-recall successes in Experiment 1 showed that the probability of their recognition given recall was .983 ; in Experiment 2, the probabilities were .860 (strict scoring) and 1.00 (lenient scoring). ${ }^{2}$ This relation of dependency seems intuitively the more likely outcome, for neither in recognition nor in free recall is the study list context reinstated, and it is the outcome expected from the Tulving-Wiseman law.

There seems little doubt that under normal test conditions, the relation between recall and recognition for freerecallable words is one of dependence, because this result was also obtained in each of a series of experiments by Watkins and Todres (1978). In these experiments, the cuereduction method of Tulving and Watkins (1975) was used to estimate the probability of an item being in a recallable state but not in a recognizable state, and it was estimated to be essentially zero. Thus, as Watkins and Todres concluded, "under the general conditions of the present experiments the set of recallable items is substantially if not wholly included within the set of recognizable items" (1978, p. 632). Recall, under these conditions, was really free recall; it involved recall of a large number of target words (36) from a single category cue. The findings and conclusions of Watkins and Todres are consistent with the relation observed between recall and recognition of free-recallable items in the present experiments.

In another series of experiments, Broadbent and Broadbent (1975) reached the opposite conclusion. They concluded that recall and recognition were essentially independent, but their conclusion was based on another procedure in which recognition performance for nonrecalled items from a previous free-recall test was compared with recognition performance for the whole list (or a matched subset thereof) when no recall was required. Thus, in effect, if not in deed, the Broadbents' conclusions were based on free-recall failures, and their findings and conclusions are consistent with the relation observed between recall and recognition of free-recall failures in the present experiments.

It seems unlikely that the close parallel between the present observations and those of Watkins and Todres (1978) and Broadbent and Broadbent (1975) is entirely fortuitous. If it is not, then the present findings and conclusions provide a solution to the hitherto unsolved puzzle as to why these two previous sets of studies reached such contrary conclusions about the nature of the relation between recall and recognition.

\section{REFERENCES}

Bahrick, H. P. (1970). Two-phase model for prompted recall. Psychological Review, 77, 215-222.

BAHRick, H. P. (1979). Broader methods and narrower theories for memory research: Comments on the papers by Eysenck and Cermak. In L. S. Cermak \& F. I. M. Craik (Eds.), Levels of processing in human memory (pp. 141-156). Hillsdale, NJ: Erlbaum.

Broadbent, D. E., Brondbent, M. H. (1975). The recognition of words which cannot be recalled. In P. M. A. Rabbitt \& S. Dornic (Eds.), Attention \& Performance (Vol. 5, pp. 575-590). New York: Academic Press.

Flexser, A. J., \&ulving, E. (1978). Retrieval independence in recognition and recall. Psychological Review, 85, 153-171.

Gardiner, J. M., Tulving, E. (1980). Exceptions to recognition failure of recallable words. Journal of Verbal Learning \& Verbal Behavior, 19, 194-209.

Glass, A. L., Holyoak, K. J. (1986). Cognition (2nd ed.). New York: Random House.

GrEGG, V. H. (1986). Introduction to human memory. London: Routledge \& Kegan Paul.

JoNES, G. V., \& GARDINER, J. M. (1988). Recognition failure with identical retrieval cues. Manuscript submitted for publication.

KINTSCH, W. (1974). The representation of meaning in memory. Potomac, MD: Erlbaum.

KINTSCH, W. (1978). More on recognition failure of recallable words: Implications for generation-recognition models. Psychological Review, 85, 470-473.

MARTIN, E. (1975). Generation-recognition theory and the encoding specificity principle. Psychological Review, 82, 150-153.

Muter, P. (1984). Recognition and recall of words with a single meaning. Joumal of Experimental Psychology: Leaming, Memory \& Cognition, 10, 198-202.

Nilsson, L. G., Dinniwell, M., \& Tulving, E. (1987). Recognition failure of categorized words. Memory \& Cognition, 15, 389-396.

Nilsson, L. G., LAw, J., \& Tulving, E. (1988). Recognition failure of recallable unique names: Evidence for an empirical law of memory and learning. Joumal of Experimental Psychology: Learning, Memory, \& Cognition, 14, 266-277.

Reder, L. M., ANDerson, J. R., \& Bjork, R. A. (1974). A semantic interpretation of encoding specificity. Journal of Experimental Psychology, 102, 648-656.

TulviNG, E. (1976). Ecphoric processes in recall and recognition. In J. Brown (Ed.), Recall and recognition (pp. 37-73). London: Wiley.

Tulving, E. (1983). Elements of episodic memory. Oxford: Clarendon Press.

Tulving, E., \& Thомson, D. M. (1973). Encoding specificity and retrieval processes in episodic memory. Psychological Review, 80, 352-373. 
Tulving, E., W WAtKins, M. J. (1975). Structure of memory traces. Psychological Review, 82, 261-275.

Tulving, E., \& Watkins, O. C. (1977). Recognition failure of words with a single meaning. Memory \& Cognition, 5, 513-522.

Tulving, E., Wiseman, S. (1975). Relation between recognition and recognition failure of recallable words. Bulletin of the Psychonomic Society, 6, 79-82.

Watkins, M. J., \& GARDiner, J. M. (1979). An appreciation of generate-recognize theory of recall. Journal of Verbal Learning \& Verbal Behavior, 18, 687-704.

WATKINS, M. J., Todres, A. K. (1978). On the relation between recall and recognition. Joumal of Verbal Learning \& Verbal Behavior, 17, 621-633.

WatkINs, M. J., \& Tulving, E. (1975). Episodic memory: When recognition fails. Journal of Experimental Psychology: General, 1, 5-29.

\section{NOTES}

1. The data presented in Table 1 might alternatively have been presented by partitioning cued recall between free-recall failures and free-recall successes, rather than by comparing free-recall failures with overall cued recall. It seemed more appropriate, however, to present the data so that they could be directly compared with previous recognition failure studies.

2. The probabilities for recognition given free recall in the free-recall test were almost identical, since virtually all words in a free-recallable state were recalled in both the free-recall and cued-recall tests.

(Manuscript received March 24, 1987; revision accepted for publication January 15, 1988.) 